\title{
CRESCIMENTO DA AUTOMATIZAÇÃO DOS ELETRÔNICOS COM UTILIZAÇÃO DOS SISTEMAS EMBARCADOS: REVISÃO DE LITERATURA
}

\author{
Eliane Nunes Costa ${ }^{1}$ \\ Juliana Facchini de Souza ${ }^{2}$ \\ Marcio José Sembay ${ }^{3}$ \\ Ingrid Solange Sepúlveda Muñoz ${ }^{4}$
}

Resumo: Este artigo traz a junção de várias teorias de conhecimento que foram aplicadas através da utilização de Sistemas Embarcados. O objetivo do presente artigo é demonstrar que para o crescimento da automatização na tecnologia atualmente, não há limites para a criação de novos projetos, sejam eles grandes ou pequenos, proporcionando construções de ambientes cada vez mais inteligentes e interativos, nos quais os Sistemas Embarcados são utilizados para melhorar cada vez mais atividades comuns do dia a dia. Foi realizado uma pesquisa de trinta artigos onde foi possível concluir que a utilização dos Sistemas Embarcados é uma solução utilizada nas mais diversas atividades cotidianas.

Palavras-chave: Sistemas Embarcados; Solução; Atividades; Microcontroladores.

\footnotetext{
1 Ciência da Computação, Centro Universitário Unifacvest, Brasil. E-mail: liacats@hotmail.com@hotmail.com.

2 Ciência da Computação, Centro Universitário Unifacvest, Brasil. E-mail: jufacchini1@gmail.com.

${ }^{3}$ Ciência da Computação, Centro Universitário Unifacvest, Brasil. E-mail: m_sembay@yahoo.com.br.

4 Ciência da Computação, Centro Universitário Unifacvest, Brasil. E-mail: ismunoz3@gmail.com.
} 